\title{
Knowledge and Attitude Regarding Major Risk Factors of Cardiovascular Diseases among 15-19 Year Old Students of Kathmandu District
}

\begin{abstract}
Background: Cardiovascular diseases are the leading cause of morbidity and mortality worldwide. Studies have shown that some people are at greater risk of developing cardiovascular disease than others. The major factors which increase the risks are tobacco chewing/smoking, raised blood cholesterol level, high blood pressure, physical inactivity, overweight and obesity, excessive alcohol consumption, age, sex and heredity. Although cardiovascular diseases typically occur in middle age or later, risk factors are determined to a great extent by behaviours learnt in childhood and continued into adulthood. Throughout the world, these risks are starting to appear earlier. Findings of various studies worldwide suggested that adolescents lacked knowledge regarding the risk of cardiovascular diseases and did not perceive themselves at risk for cardiovascular diseases.
\end{abstract}

Methodology: A cross-sectional study was conducted among 144 adolescent students of grade XI and XII in one public and one private higher secondary schools of Kathmandu district. Samples were chosen purposively. Data were collected with the help of semi structured self administered questionnaire. Questionnaire was based on Likert scale. Data analysis was performed by using Statistical Package for Social Science - 17.0 for windows.

Results: Overall 36.8 percent of respondents had good knowledge, 55.6 percent had fair knowledge and the remaining 7.6 percent had poor knowledge regarding the major risk factors of cardiovascular diseases. Sources of health information was found statistically significant $(p=0.004)$ with the knowledge of respondents. Regarding overall attitude, the majority $(47.9 \%)$ had the neutral attitude followed by positive $(31.9 \%)$ and one fifth possessed negative attitude. Knowledge versus attitude regarding the major risk factors of cardiovascular diseases was found statistically significant $(\mathrm{p}=0.002)$.

Conclusion: Results of this study revealed that good knowledge as well as positive attitude towards major risk factors of cardiovascular diseases among the adolescent students is unsatisfactory. Socio-demographic factors for good knowledge and good knowledge for the development of positive attitude play vital role.

Key words: Knowledge, Attitude, Major risk factors, Cardiovascular Diseases, Adolescent
Yadav KD, ${ }^{1}$ Wagle RR $^{2}$

${ }^{1}$ Micronutrient Initiative, Hetauda Field Office, Hetauda-4, Nepal ${ }^{2}$ Department of Community Medicine and Public Health, Maharujgunj Medical Campus, Institute of Medicine, TU, Nepal

\section{Introduction}

Cardiovascular diseases (CVDs) are a group of disorders of the heart and blood vessels. (1) These are the leading cause of morbidity and mortality worldwide. (2) The South Asian countries Nepal, India, Pakistan, Sri-Lanka and Bangladesh contribute most to the worldwide CVDs burden. (3) In Nepal, it is estimated that $5.6 \%$ of people living in the mountains, $1.5 \%$ in the hills and $5 \%$ of people in the Terai region suffer from CVDs. (4)

Studies have shown that some people are at greater risk of cardiovascular disease than others. Factors linked to an increased risk of developing cardiovascular disease are heredity or family history, age, sex, tobacco chewing/smoking, raised blood cholesterol level, high blood pressure (BP), physical inactivity, excessive alcohol consumption, overweight and obesity. (5) Although cardiovascular diseases typically occur in middle age or later, risk factors are determined to a great extent by behaviors' learnt in childhood and continued into adulthood, such as dietary habits and smoking. Throughout the world, these risks are starting to appear earlier. Physical activity decreases markedly in adolescence. (6)

Findings of various studies worldwide suggested that adolescents lacked knowledge regarding the risk of cardiovascular diseases and did not perceive themselves at risk for cardiovascular diseases. A study conducted among the 873 students of grades (9-12) from four high schools of Michigan, USA in 2005 showed that $40 \%$ of respondents incorrectly chose a substance abuse/use behavior, other than cigarettes, as the most important cardiovascular disease risk behavior. (7)

In an another study conducted among 1,503 college students at state university of New York at Plattsburgh in 1990 found that over $91 \%$ of respondents knew hypertension was a major cardiovascular risk factor. In addition, $90 \%$ identified smoking, $86.7 \%$ identified cholesterol level, and $72 \%$ identified exercise as additional factors. (8)

Similar study conducted among school children attending classes 9 to 12 at the two Kendriya Vidyalayas located at Pune Cantonment in 2007 found that only $88 \%$ of intermediate and $71 \%$ of high school children considered heart disease to be an important public health problem. Out of these, many

CORRESPONDENCE : Krishna Dev Yadav, Field Officer, Micronutrient Initiative, Hetauda Field Office, Hetauda-4, Kamaldanda, Makwanpur, Nepal. Email: 2yadavkrishnadeo@gmail.com 
(nearly 40\%) considered heart disease relevant for people over 50 years. Only $42.6 \%$ of all students were of the opinion that coronary heart disease is preventable. Smoking, obesity and reduced physical activity were perceived as important top three risk factors for coronary heart disease. However, a very small percentage could identify raised serum cholesterol or hypertension as important risk factors. (9)

A study conducted in Nepal showed that the mean age of the start of smoking was found to be 18.8 years for men and 12.9 years for women. Similarly more than half of the Nepalese men and almost one fifth of the Nepalese women were found current tobacco users. Study also revealed that more than one fourth of the respondents were found to be current users of alcoholic drinks. Around $9 \%$ of the population was found to have reported prevalence of high $\mathrm{BP}$ as told by their health care professional. And around $7 \%$ in both sexes were identified overweight whereas out of total respondents, more than $80 \%$ were found having either one or more risk factors.(10)

It is therefore important to assess the knowledge and attitude regarding the major risk factors of cardiovascular diseases among the adolescent students. This study also tries to analyze the underlying factors associated with the knowledge and attitude of the respondents so that risk factors can be reduced by implementing appropriate intervention measures.

\section{Methods}

A descriptive, cross sectional, quantitative study was conducted among 15-19 years old adolescent students of Kathmandu district. The study took place after the approval of research proposal by the institutional review board at the Department of Community Medicine and Family Health, Institute of Medicine, Tribhuvan University. The questionnaire for the survey was constructed taking reference of WHO STEPS Manual for chronic disease. Widely used Likert scale was applied to measure the particular and overall attitude. The questionnaire was prepared in Nepali, a local language, so that students could understand the questions easily. Questionnaire was pretested. Before the survey conduction purpose of the study was explained and verbal consent was taken from school administration as well as from the students. Samples were selected purposively. Selected schools were from Maharajgunj area of Kathmandu district. Among the two schools selected, one was public (Shivapuri Higher Secondary School) and another was private (Orient International College). Two sections; one from grade XI and another from grade XII were chosen from both of the schools. Data were collected with the help of self administered semi structured questionnaire. Out of total 492 students enrolled in grade XI \& XII; 144 (29.3\%) were involved (75 from grade XI and 69 from XII) in the study. Data analysis was performed by using SPSS 17.0 for Windows. Non-parametric chi-square test was applied to test the statistical significance of cross tabulated data. Study took place during the month of November 2010.

\section{Results}

Socio-demographic characteristics of the study population

Median age of the respondents was 17 years. Sex ratio was 1.03 (M: F). Brahmin/Chhetri comprised 47.9 percent followed by Mongolians (26.4\%) and Newar (19.4\%). Other castes (Majhi, Pariyar, Tharu etc) comprised 6.3 percent. Major religion was Hindu (84\%) followed by Buddhism (11.8\%) and 4.2 percent were Christian. Most of the respondents (83.3\%) belonged to middle class family followed by higher class $(14.5 \%)$ and 2.08 percent were from lower class family. Similarly 20.8 percent of respondents' father and 46.5 percent of respondents' mother had no formal education. Service, agriculture, business and housewife were the major occupations of the respondents' parents. Regarding the query on whether they had ever known anyone (family/ friends/relatives) diagnosed as CVD, remarkable percent $(42.4 \%)$ responded as "yes". Similarly regarding the query about main source of health information, the majority (44.5\%) responded that they were getting the health information from electronic media (TV, Radio, Internet) followed by family/ friends/health worker $(28.4 \%)$ and from printing media such a newspaper, text curricular books etc. (27.1\%).

\section{Knowledge regarding the major risk factors}

The highest proportion of respondents (91.7 percent) identified tobacco chewing/ smoking as a risk factor followed by excessive alcohol consumption (88.9\%), high cholesterol diet $(87.5 \%)$, high BP $(86.1 \%)$, obesity/overweight (69.4\%), physical inactiveness $(59.7 \%)$ and old age $(52.8 \%)$. The proportion of respondents who identified heredity as a risk factor of CVDs was 48.6 percent.

Table 1: Knowledge grading regarding the CVD risk factors $(n=144)$

\begin{tabular}{l|c|c}
\hline \multicolumn{1}{c|}{ Knowledge Grading } & Number $(\mathrm{n})$ & Percent (\%) \\
\hline Poor (<4 right response) & 11 & 7.6 \\
\hline Fair (4 - 5 right response) & 80 & 55.6 \\
\hline Good (>5 right response) & 53 & 36.8 \\
\hline Total & 144 & 100.00 \\
\hline
\end{tabular}

Analysis of knowledge by socio-demographic characteristics of respondents

Findings showed that good knowledge was higher in males $(42.5 \%)$ than the females $(31.0 \%)$. The highest shre of good knowledge $(53.6 \%)$ was possessed by Newar as compared against other ethnicities. Similarly good knowledge was found highest among respondents of higher class family (38.1\%) followed by middle class (36.7\%) and lower class (33.3\%). Findings also showed that good knowledge in respondents was directly proportional to their parents' educational status. Similarly good knowledge was found higher (41.0\%) among those respondents who had ever known someone diagnosed as CVDs. Those who had responded family friends/health workers as main source of health information had higher good 
knowledge (43.9\%) and it was statistically significant $(\mathrm{p}=0.004)$ at 5 percent of significance level.

\section{Attitude regarding major risk factors:}

Attitude of respondents regarding the major risk factors of CVDs was assessed through already pretested eight attitude testing statements based on the Likert scale.

Regarding the statement "CVD is an old age problem so I don't care" two third $(66.7 \%)$ of the respondents showed their strong disagreement followed by disagreement (18.1\%). Regarding the statement "CVD is either heredity hereditary problem or not, I don't care" majority (55.6\%) of respondents showed their strong disagreement followed by disagreement (22.9\%). Similarly, regarding the statement "High BP is a minor problem so no need to worry about" 30.6 percent of respondents showed their strong disagreement as well as disagreement followed by agreement $(21.5 \%)$. Regarding the statement "Majority of physically inactive people get CVD" 46.5 percent of respondents showed their agreement followed by strong agreement (25\%). Likewise, attitude regarding the statement "Tobacco chewing/smoking cause CVD; not sure" 35.4 percent of respondents showed their strong disagreement followed by disagreement (26.4\%). Similarly, attitude regarding the statement "Over weight: godown of diseases/CVD" more than half $(52.1 \%)$ of respondents showed their agreement followed by strong agreement $(26.4 \%)$. Regarding the statement "Fatty diet taking old people are still alive" more than one third $(34.7 \%)$ of respondents showed their disagreement followed by strong disagreement (29.2\%). Similarly, regarding the statement "Consumption of excessive alcohol is to invite CVD" 42.4 percent of respondents showed their agreement followed by strong agreement (41.7\%).

Table 2: Attitude grading regarding CVD risk factors $(n=144)$

\begin{tabular}{l|c|c}
\hline \multicolumn{1}{c|}{ Knowledge Grading } & Number $(\mathrm{n})$ & Percent (\%) \\
\hline Negative (<4 positive response) & 29 & 20.1 \\
\hline Neutral (4-5 positive response) & 69 & 47.9 \\
\hline Positive (>5 positive response) & 46 & 31.9 \\
\hline Total & 144 & 100.00 \\
\hline
\end{tabular}

\section{Analysis of attitude by socio-demographic} characteristics of respondents

Findings showed that positive attitude regarding the risk factors of CVDs was higher in boys (34.2\%) than in girls (29.6\%) whereas negative attitude was higher in girls (25.4\%) than in boys (15.1\%). Brahmin/Chhetri, Newar and Mongolians possessed quite similar (31\%-35\%) positive attitude whereas the others ethnic groups possessed very low positive attitude (11.1\%) but the highest negative attitude (44.4\%). Respondents having low family economic status possessed higher negative attitude $(33.3 \%)$ and vice versa. Similarly positive attitude was also found to be corresponding with parents' educational status i.e. higher the parents educational status higher the positive attitude of the respondents (44.4\%) and lower the educational status higher the negative attitude $(22.4 \%)$. Respondents who were using electronic media as a source of health information were found to possess higher positive attitude $(35.9 \%)$.

Table 3: Knowledge versus attitude regarding CVD risk factors $(n=144)$

\begin{tabular}{l|r|r|r|r}
\hline \multirow{2}{*}{ Knowledge } & \multicolumn{4}{|c}{ Attitude regarding CVD risk factors } \\
\cline { 2 - 5 } & Negative & \multicolumn{1}{c}{ Neutral } & Positive & p-value \\
\hline Poor & $6(54.5)$ & $4(36.4)$ & $1(9.1)$ & $0.002^{*}$ \\
\hline Fair & $17(21.3)$ & $43(53.8)$ & $20(25.0)$ & \\
\hline Good & $6(11.3)$ & $22(41.5)$ & $25(47.2)$ & \\
\hline
\end{tabular}

Note: Values in parenthesis denote the percentage.

* Statistical significance was checked at 5 percent of significance level

\section{Discussion}

Findings suggested that adolescent students lacked overall knowledge regarding the major risk factors of cardiovascular diseases and it was consistent with the study conducted among the students of grades (9-12) from four high schools of Michigan, USA in 2005. (7)

The number of respondents who knew high blood pressure as risk factor $(86.1 \%$ ) was lower (over $91 \%$ ), tobacco chewing/ smoking $(91.7 \%$ ) was slight more (over 90\%), physically inactive $(59.7 \%$ ) was lower (over $72 \%$ ) than reported by Richard Frost, MD, in study conducted in students of State University of New York at Plattsburgh in 1990. (8)

The number of respondents who had shown positive attitude regarding the risk factors such as physically inactive $(71.5 \%)$ was lower (over $88 \%$ ), tobacco chewing/smoking (61.8\%) was higher (over 55\%), high fatty, oily/cholesterol diet (63.9\%) was lower (over 91\%) than that of the study conducted in University students of Karachi, Pakistan in 2005. (11)

The findings of the study revealed that boys possessed more "good knowledge" than girls. This difference can partly be explained by the patriarchal society where gender discrimination is more prevalent. Usually boys have higher opportunity to receive information as they are more exposed to the outer world than girls. The findings of the study emphasized the influence of socio-demographic variables on the level of knowledge. Knowledge regarding major risk factors varied among different ethnic groups. Respondents belonging to Newar ethnic group had highest "good knowledge" followed by Brahmin/Chhetri, Mongolian and others respectively. This might be because to Newars are indigenous group of Nepal's Kathmandu valley and Brahmins/ Chhetri are forward advantageous group since ancient times. Findings also showed that good knowledge in respondents was directly proportional to their parents' educational status. Therefore it can be said that parents' education definitely 
played some role in the respondents' knowledge. It might be because educated parents taught their children about the healthful behaviors. Regarding the main source of health information good knowledge was found highest (43.9\%) among the human resource users followed by printing media $(30.7 \%)$ and electronic media $(28.1 \%)$. This might be due to easy availability of free suggestions in our society by people.

Positive attitude was found higher among the respondents who preferred the printing media as main source of health information. It might be due to in depth information that we could get from printed materials such as newspaper, books etc.

Finding of knowledge versus attitude also showed that those who had higher knowledge possessed positive attitude and vice versa. This might be due to the need of knowledge for the attitude formation.

\section{Conclusion}

Results of the study showed that good knowledge and positive attitude regarding the major risk factors of CVDs among the adolescent students of Kathmandu district are unsatisfactory. Similarly findings also revealed that sociodemographic factors for the development of good knowledge and good knowledge for the development of positive attitude plays vital role. Due to the changing life style of Nepalese people these days, they are more susceptible to life style related diseases like CVDs. Therefore to prevent CVDs, timely adoption of healthful habits is a must and the very age group for this is adolescence. Adolescent centered activities that can raise knowledge and develop positive attitude towards CVDs risk factors are strongly recommended so that healthful habits can be formed.

\section{Acknowledgement}

I would like to express my sincere gratitude to the Department of Community Medicine and Family Health, Institute of Medicine for providing me an opportunity to conduct this research. I would also like to extend my profound gratitude to my research supervisor Prof. Dr. Rajendra Raj Wagle for his nonstop guidance and meticulous editing of solecisms.

\section{References}

1. who.int [homepage on the internet]. World Health Organization/ Cardiovascular diseases Online fact sheet, c 2009 [updated 2009 Sep; cited 2010 Jun 3].Available from: http://www.who.int/ mediacentre/factsheets/fs317/en/index.html

2. Limbu YR, Maskey A, K.C. Man Bahadur, Malla R, Sharma D, Shrestha NK. A Study on Cardiovascular Disease Pattern of Admitted Cases in Newly Emerged National Heart Centre. J N M A [serial online]. 2001 [cited 2010 Jun 12]; 41:284-288. Available from: URL:http://www.jnma.com.np/files/archive

3. nhv.se [homepage on the internet]. Nordic School of Public Health: Non-communicable diseases in Nepal Online resources; c1998-2000 [updated 2009 May; cited 2010 Jul 24]; Available from: http://www.nhv.se/customer/templates/InfoPage 1973.aspx?epslanguage $=\mathrm{EN}$
4. Shankar PR, Partha P, Shenoy N, Chandrasekhar TS, Dubey AK. Knowledge about heart attack and hypertension among individuals attending a cardiac camp in Pokhara city. K U Med J [serial online] 2007 [cited 2010 Jun 3]; 5(2): 273-278. Available from: http://www.ncbi.nlm.nih.gov/pubmed/18604037

5. nevdgp.org.au [homepage on the internet].Heart foundation of Australia: Risk factors for heart disease Online resources; c2002 [updated $2004 \mathrm{Jul}$; cited 2010 Jun 3]; Available from: http:// www.nevdgp.org.au/info/heartf/school/risk.htm.

6. who.int [homepage on the internet]. World Health Organization/ Cardiovascular diseases: Risk factors starts in childhood and youth Online cvd atlas; c2002 [updated 2004; cited 2010 Jun 3]; Available from: http://www.who.int/cardiovascular_diseases/en/ cvd_atlas_04_childhood_youth.pdf.

7. Vanhecke TE, Miller WM, Franklin BA, Weber JE, Mcculloud PA. Awareness, knowledge, and perception of heart disease among adolescents. E J C P R [serial online] 2006 Feb [cited 2010 Aug 15]; 13(5): 718-723. Available from: http://cpr.sagepub.com/ content/13/5/718.abstract

8. Frost R. Cardiovascular risk modification in the college student: Knowledge, attitudes and behaviors. G J I M [serial online] 1992 Nov [cited 2010 Jun 12]; 7(3): 317-320. Available from: http:// www.springerlink.com/content/922858x471513107/

9. Banerjee A. Coronary heart disease: Awareness of risk factors and lifestyle among school-going adolescents. Indian J Med Sci [serial online] 2007 [cited 2010 Jun 12]; 61:474-6. Available from: http://www.indianjmedsci.org/text.asp?2007/61/8/474/ 33713

10. WHO STEPS Surveillance: Non Communicable Disease Risk Factors Survey 2008. Nepal: Ministry of Health and Population, Government of Nepal, Society for Local Integrated Development Nepal and WHO; 2009. p. 2-7.

11. Almas A, Hameed A, Sultan FA. Knowledge of Coronary Artery Disease (CAD) risk factors and Coronary Intervention among University Students. JPMA [Serial Online]. 2008 Oct [cited 2010 Aug 15]; 58:553. Available from: http://jpma.org.pk/ full_article_text.php?article_id=1512. 